\title{
Two-Dimensional and Three-Dimensional Single Particle Tracking of Upconverting Nanoparticles in Living Cells
}

\author{
Kyujin Shin ${ }^{\dagger}$, Yo Han Song ${ }^{\dagger}$, Yeongchang Goh and Kang Taek Lee * \\ Department of Chemistry, School of Physics and Chemistry, Gwangju Institute of Science and Technology (GIST), \\ Gwangju 61005, Korea; shinkj@gist.ac.kr (K.S.); yhsong@gist.ac.kr (Y.H.S.); kyc940409@gist.ac.kr (Y.G.) \\ * Correspondence: ktlee@gist.ac.kr; Tel.: +82-62-715-3685 \\ + These authors contributed equally to this work.
}

Received: 8 January 2019; Accepted: 19 March 2019; Published: 21 March 2019

\begin{abstract}
Lanthanide-doped upconversion nanoparticles (UCNPs) are inorganic nanomaterials in which the lanthanide cations embedded in the host matrix can convert incident near-infrared light to visible or ultraviolet light. These particles are often used for long-term and real-time imaging because they are extremely stable even when subjected to continuous irradiation for a long time. It is now possible to image their movement at the single particle level with a scale of a few nanometers and track their trajectories as a function of time with a scale of a few microseconds. Such UCNP-based single-particle tracking (SPT) technology provides information about the intracellular structures and dynamics in living cells. Thus far, most imaging techniques have been built on fluorescence microscopic techniques (epifluorescence, total internal reflection, etc.). However, two-dimensional (2D) images obtained using these techniques are limited in only being able to visualize those on the focal planes of the objective lens. On the contrary, if three-dimensional (3D) structures and dynamics are known, deeper insights into the biology of the thick cells and tissues can be obtained. In this review, we introduce the status of the fluorescence imaging techniques, discuss the mathematical description of SPT, and outline the past few studies using UCNPs as imaging probes or biologically functionalized carriers.
\end{abstract}

Keywords: upconversion nanoparticles; single-particle tracking; three-dimensional imaging; intracellular transport

\section{Introduction}

The synthesis and characterization of lanthanide-doped upconversion nanoparticles (UCNPs) are well established [1-6]. In particular, UCNPs, which are doubly doped by the sensitizer cations (usually $\mathrm{Yb}^{3+}$ ) and the activator cations (e.g., $\mathrm{Yb}^{3+}, \mathrm{Er}^{3+}, \mathrm{Tm}^{3+}, \mathrm{Nd}^{3+}, \mathrm{Ho}^{3+}$ ) in the host material (e.g., $\mathrm{NaYF}_{4}$, $\mathrm{NaGdF}_{4}$ ), have attracted the greatest interest [4,5]. By selecting a proper cation pair and adjusting their relative composition, their optical properties can be optimized, such as wavelengths, band-width, quantum yield, and photo stability [1,4]. UCNPs are excited by near-infrared (NIR) lasers, whose wavelength is well matched to the absorption wavelength of $\mathrm{Yb}^{3+}(980 \mathrm{~nm})$ and $\mathrm{Nd}^{3+}(808 \mathrm{~nm})$ [1-5]. In this NIR range, biomolecules show minimum absorption in vitro and in vivo [7-12]. As a result, they do not damage the biological samples (cells and tissues) optically and chemically. Thus, UCNPs can be monitored for a long time [13,14]. In addition, for the same reason, the autofluorescence is nearly absent, while this side effect is problematic even in confocal microscopy $[15,16]$. Finally, NIR can penetrate into the tissues and skins as deep as a few $\mathrm{cm}$ due to the lower scattering and absorption compared to visible or UV light, which would be beneficial when UCNPs are employed in medical 
applications [17-20]. Other than the benefits due to the NIR excitation, the upconversion process itself confers huge advantages. Their emission upon continuous irradiation of NIR was found to be free of blinking and bleaching [21-23]. Thus, UCNPs combined with NIR excitation will help researchers to receive successful long-term and real-time images or movies [13,14,16,24]. Being free from autofluorescence, these movies provide the accurate coordinates of UCNPs as a function of time. The duration of such "tracking" of particles and the length of trajectories are obviously connected to the photostability of the probes (organic dyes, fluorescence proteins, and nanoparticles) [25-28]. In that respect, UCNPs are considered ideal for optical imaging due to their photostability, as described above [3,4]. However, the data analysis for determining the coordinates is not trivial because one has to obtain the images of individual particle signals that are well separated spatially without significant overlap. In order to deal with such a situation, several versions of super-resolution fluorescence microscopy using UCNPs have been recently developed and are widely used [23,29-32]. In this review, we introduce the status of the fluorescence imaging techniques with an emphasis on the benefits of three-dimensional (3D) imaging over the conventional two-dimensional (2D) version (and b). After this, we discuss the mathematical description of SPT (Figure 1c) and the past few studies, using UCNPs as imaging probes or biologically functionalized carriers.

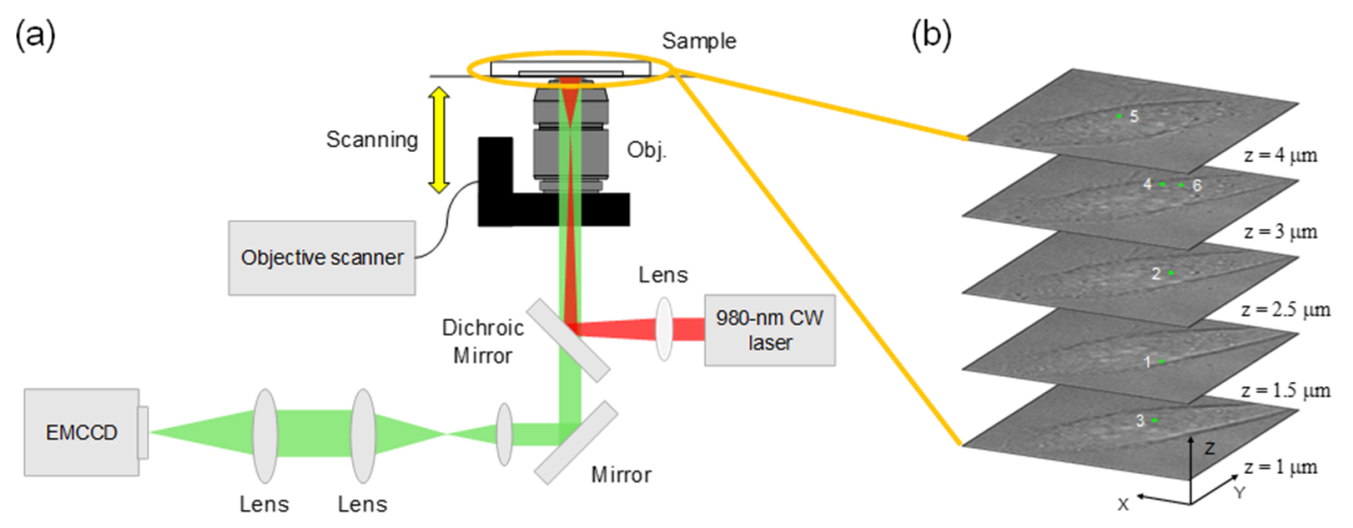

(c)

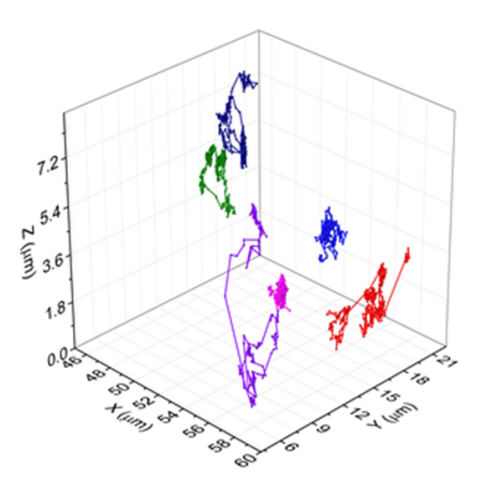

Figure 1. (a) Wide-field epi-fluorescence microscopy setup for 3D imaging and tracking. (b) Five representative single-cell images containing UCNPs at different heights. (c) 3D trajectories of six single UCNP vesicles.

\section{Single-Particle Tracking}

\subsection{Principle}

In biological science studies, SPT may be significantly more informative than any other methods [25-27,33]. Literally, SPT analysis tracks the position of single particles (e.g., a single nanoparticle, vesicle, or endosome). To construct the trajectories of single particles, the center position of particle is connected by a tracking algorithm [25-27]. It is possible to obtain various quantitative 
analyses about the motion by using the obtained trajectories. As the imaging probe, UCNPs might be compared to semiconductor quantum dots (QDs) in many ways. For example, the absorption wavelength of QDs is spectrally broad while the emission is narrow, and its wavelength depends strongly on the size (the smaller the bluer) due to the quantum confinement effect [34-36]. On the contrary, UCNPs are usually excited at a single wavelength $(980$ or $808 \mathrm{~nm}$ ) and their emission is blue-shifted (i.e., towards higher frequencies) [1,2]. It is important to note that the spectra of UCNPs do not depend on their size, which indicates that any variations in the particle dimensions (usually from sub-10 nm to several hundred $\mathrm{nm}$ ) do not affect their photophysical properties $[37,38]$.

\subsection{Localization of Single Particles}

To track a single fluorophore, its coordinates need to be accurately determined. If we assume that the fluorophore is a point source of the photon emission, the real image is a large spot due to the diffraction limit of light. This spot signals display the shape of a function. This function, which is known as the "point-spread function (PSF)," is defined as the optical instrument response function of the microscope. In a typical experimental setup, such PSFs are isotropic and contain the information about the coordinates $[27,39,40]$. On the focal plane, a PSF is fit to a 2D Gaussian functions, by which the $x$ - and y-coordinates are determined (Figure 2b) [39]. Although the Airy function may be the best choice as a model PSF, most localization studies adopt the Gaussian function (Equation (1)) instead of the Airy function (Equation (2)) because the Gaussian function is much easier to handle and the localized centroids are accurate enough [27].

$$
\text { Gaussian for } \mathrm{x}-\mathrm{y} \text { plane } \equiv A \cdot \exp \left(-\frac{\left(x-x_{0}\right)^{2}+\left(y-y_{0}\right)^{2}}{2 \sigma^{2}}\right)
$$

$A$ : amplitude of Gaussian, $\sigma$ : standard deviation of Gaussian

$$
\text { Airy function } \equiv\left(\frac{2 J_{1}\left(\frac{2 \pi}{\lambda} N A \sqrt{\left(x-x_{0}\right)^{2}+\left(y-y_{0}\right)^{2}}\right)}{\frac{2 \pi}{\lambda} N A \sqrt{\left(x-x_{0}\right)^{2}+\left(y-y_{0}\right)^{2}}}\right)^{2}
$$

$J_{1}(X)$ : the first order Bessel function, $\lambda$ : wavelength of emission, $N A$ : numerical aperture

The center, which is the point where the Gaussian function is maximum, is defined as twodimensional $x$ - and $y$ - coordinates $[27,40]$. The accuracy of localization can be estimated by the following equation [39]:

$$
\Delta x=\sqrt{\frac{\sigma^{2}+a^{2} / 12}{N}+\frac{8 \pi \sigma^{4} b^{2}}{a^{2} N^{2}}} \approx \sqrt{\frac{\sigma^{2}+a^{2} / 12}{N}},
$$

where $\sigma$ is the standard deviation of the fitting Gaussian function, a is the pixel size, $b$ is the background noise, and $\mathrm{N}$ is the photon number. In practice, the second term is negligibly small [39]. In this equation, it is noteworthy that the accuracy is closely related to the number of photons detected. The $s$ and a values depend on the optical setup and the camera technology, so these cannot be controlled [39]. However, the number of photons $(\mathrm{N})$ is the number related to the intrinsic stability of the fluorophore against irradiation or excitation $[27,39,40]$. A high $\mathrm{N}$ value can be achieved by raising the power of the light source (laser). However, the fluorophores would become photobleached and disappear from the images more frequently. This is why people are concerned about the photostability or quantum yield of their probes (organic dyes) $[23,27,28]$. What about UCNPs? The quantum yield of UCNPs is generally very low $(<1 \%)$ compared to organic dyes or QDs [1,2]. However, the laser power can be raised until any saturation occurs [31]. The signal will increase accordingly, with only small damage to the cells and tissues $[10,13,14]$. 
(a)
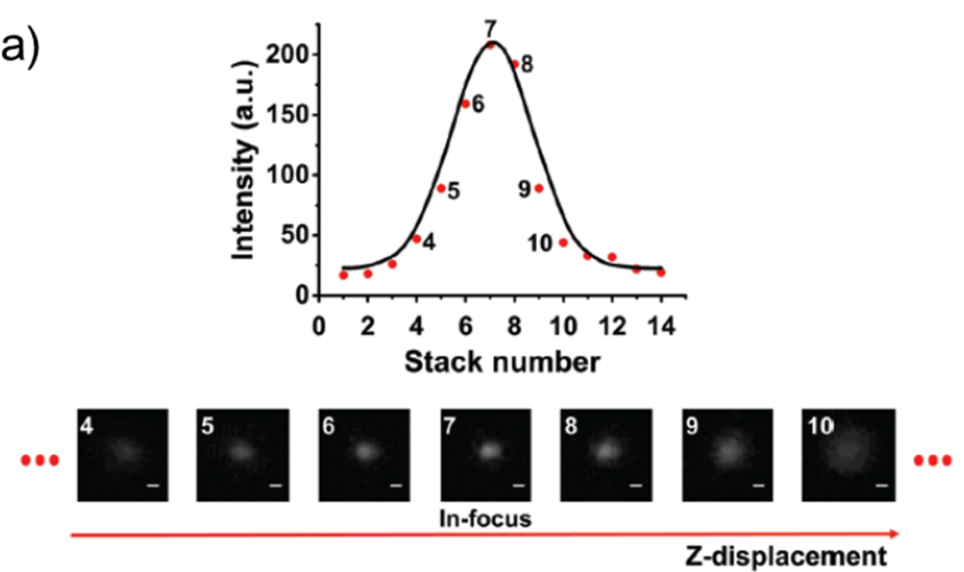

(b)

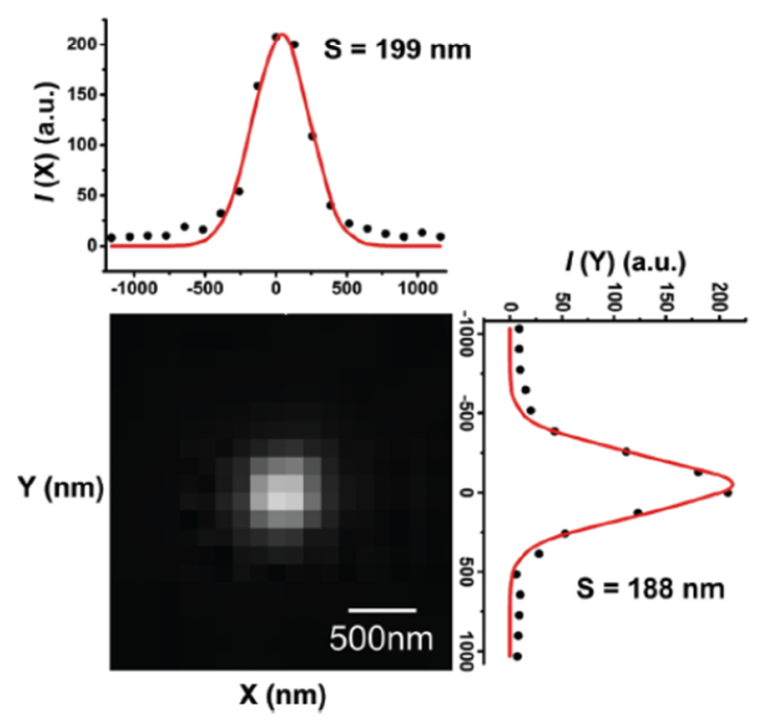

Figure 2. (a) The UCNP intensity profile over the $z$-axis and the Gaussian fit. UCNP images were acquired by $980 \mathrm{~nm}$ excitation $\left(731 \mathrm{~W} \mathrm{~cm}^{-2}\right)$ with an exposure time of 70 millisecond. Scale bar: $500 \mathrm{~nm}$. (b) A typical 3D centroid determination. The UCNP on the section image that is closest to the $\mathrm{z}$-coordinate determined in (a) is chosen for the localization. The numbers in the intensity plots represent standard deviations of the Gaussian function [16]. Reproduced by permission of the PCCP Owner Societies. Copyright 2018 Royal Society of Chemistry.

\subsection{Two-Dimensional Single-Particle Tracking}

Most SPT algorithms are built on 2D localization, whereby the center positions of the particles are determined in every frame of the movie. Various SPT algorithms have been developed, from "nearest neighbor algorithms" to more sophisticated custom algorithms, which have been reviewed previously [27,41,42]. In so doing, the research points are focused on how to identify the same particles in the subsequent frames. Chenouard et al. compared the performance of 14 different SPT algorithms for different particle dynamics (random diffusive motion, directed motion, and their combination) and concluded that no single SPT algorithm is optimal for all situations [42]. Recently, the theoretical research groups studying nonlinear statistical mechanics suggested that these mechanics may be helpful for the analysis of the trajectory in terms of velocity distribution, cumulative displacement, mean square displacement (MSD), non-Gaussian parameter (NGP) and ergodicity breaking parameter analyses $[26,27,43-45]$.

Because UCNPs do not exhibit photoblinking, their continuous movements can be monitored without interruption as long as the particles are close to the focal plane (2D space) $[13,14]$. Thus, for cells with a finite thickness, the movements along the $z$-axis are lost and only the particles moving 
on the $x$ - and $y$-axis can be investigated further $[13,14,33]$. To be frank, the particles that people have been looking at are moving by accident along the focal plane. Even the absence of photoblinking of UCNPs cannot overcome this problem [14]. However, it can be distinguished whether the UCNPs that "fade away" or "show up" in the movies are moving out of focus or in focus, respectively. In this respect, there is no way to tell which is which due to the extensive blinking of QDs. This is one of the disadvantages of $2 \mathrm{D}$ trajectories.

However, even with 2D trajectories, one may obtain substantial insights into the cellular dynamics $[14,26,33,43,46-50]$. One of the representative types of dynamics is transport by the motor proteins. Motor proteins running on the microtubule (dyneins and kinesins) or actin filament (myosin) play important roles for intracellular transport and as part of the cytoskeleton [51,52]. The consensus is that the internalization of nanomaterials occurs through a process called "endocytosis" [13,53-57]. The nanoparticles are captured by the motor proteins and transported through directional motion (anterograde, retrograde and/or bidirectional) along the microtubule and some fraction of the nanoparticles are released by exocytosis $[13,56,57]$. Such endocytic pathways form the basic concept of the drug and gene delivery [58-64]. These steps are oversimplified and the uptake rate may be stochastic or highly controlled [56,57,65-67]. The presence of multimode intracellular transport in living cells was demonstrated using long-term SPT with UCNPs [14]. Through a real-time imaging study of UCNPs in living cells, Nam et al. tracked the movement of vesicles containing UCNPs in living HeLa cells and obtained a real-time image of endocytosed UCNPs at the single vesicle level for $6 \mathrm{~h}$ [14]. The 2D SPT analysis demonstrated that the dynamics of particle transport was composed of multiple phases within a single trajectory, including active transport by motor proteins, such as dyneins and kinesins [52].

\subsection{Three-Dimensional Localization and Single Particle Tracking}

As most biological samples are 3D objects, 2D SPT has limitations, especially when one studies thick cells or tissues. The 3D localization is much more challenging than $2 \mathrm{D}$ localization because the 3D PSF is axially symmetric with respect to the focal plane and the shape changes slowly as the axial position varies [40]. Thus far, a number of 3D optical imaging techniques have been developed [68-80]. In all techniques, the researchers scan their illumination over the sample to complete 3D images [68-70]. All types of this scanning method have a vertical directional component, $z$, with respect to the $2 \mathrm{D}$ images being obtained. For example, in epifluorescence microscopy, the scanning direction of the objective lens and/or the sample stage is perpendicular to the 2D images. On the contrary, if the angle between the exciting light (e.g., lasers) and aqueous environment reaches the critical angle $\left(\sim 60^{\circ}\right)$, total internal reflection (TIR) starts to occur and a thin evanescent field that is less than $\sim 200 \mathrm{~nm}$ deep is generated on the interface $[81,82]$. Total internal reflection fluorescence (TIRF) microscopy can only be used to excite fluorophores within the field. Therefore, TIRF is not generally appropriate for the study of the cells and tissues thicker than $\sim 200 \mathrm{~nm}$.

There are various types of 3D microscopy, which use scattering or fluorescence signals for detection [69-80]. It is noteworthy that scattering microscopies were used for the 3D particle tracking. Among the various techniques, digital holographic microscopy (DHM) or interferometric scattering microscopy (iSCAT) are non-destructive "label-free" methods [71-74]. They have been developed using nonlinear scattering of light instead of using imaging probes. These are really smart and powerful methods but the focus here will be placed on the 3D SPT of UCNPs, which is applicable for observing subcellular dynamics in living cells. Previous studies have demonstrated 3D localization methods using engineered 3D PSF (e.g., double-helix PSF with fluorescence of single dyes), bifocal imaging scheme or multiplexed illumination (e.g., TSUNAMI), which is an optical aberration to understand dynamics in living cells at the single molecule level [75-80].

In astigmatism, 3D localization is a fully wide-field scheme, which is useful when the sample thickness along the $z$-axis is relatively small $[78,79]$. Zhuang and co-workers used the elliptical 
Gaussian (Equation (4)) and Airy-beam-based self-bending PSF instead of using Gaussian to fit the PSF shapes on the $x-y$ plane $[78,80,83]$.

$$
\text { Elliptical Gaussian } \equiv D \cdot \exp \left(-2\left(\frac{x-x_{0}}{w_{x}}\right)^{2}-2\left(\frac{y-y_{0}}{w_{y}}\right)^{2}\right)+b g,
$$

where $D$ is the amplitude of peak, $\left(x_{0}, y_{0}\right)$ is the center of the emitter and $b g$ is the background.

$$
\text { Image width, } w_{x, z}(z)=w_{0} \sqrt{1+\left(\frac{z-z_{0}}{d}\right)^{2}+B\left(\frac{z-z_{0}}{d}\right)^{3}+C\left(\frac{z-z_{0}}{d}\right)^{4}}
$$

where $w_{0}$ is the width of the PSF at the focal plane, $z_{0}$ is the offset of the $\mathrm{x}$ or $\mathrm{y}$ focal plane from the average focal plane, $d$ is the depth of focus and $B$ and $C$ are correction coefficients. In this case, the lateral ( $\mathrm{x}-$ and $\mathrm{y}-$ ) and axial ( $\mathrm{z}-$ ) resolutions of 3D localization are $\sim 30$ and $\sim 60 \mathrm{~nm}$, respectively [78].

Due to UCNPs' superior photostability and NIR excitation, combining 3D localization with UCNP will guarantee robust 3D tracking methodology $[16,24]$. However, the application of 3D localization methods using astigmatism and bifocal imaging is limited because the range of the z-position is relatively small $(\sim 500 \mathrm{~nm})[76,78]$. The 3D localization using multiplexed illumination microscopy requires a very sophisticated microscope [77]. On the other hand, the engineered PSF-based 3D localization, such as the double-helix PSF scheme, is regarded as a promising tool that is suitable for observing cellular dynamics by using UCNPs [75].

As noted above, the out-of-focus background due to autofluorescence is minimized, so 3D movement of all the particles can be monitored at the same time and, consequently, the location of UCNPs at the specific binding can be visualized [16,24]. The experimental approach to 3D localization of UCNPs can be categorized into two types of techniques: "z-scanning" and the "wide-field" scheme [16]. For 3D localization of UCNPs, the first step involves finding the focal plane and z-coordinate. To this end, z-scanning is performed using actuators, such as a stepping motor scanner or a piezoelectric scanner. Using a software code, the position of the objective or the sample holder on the microscope can be adjusted. While monitoring the emission intensity of a spot (Figure 2a), the distance between the objective lens and the sample are scanned. In order to find the focal plane, the UCNP intensity vs. frame number is plotted and fitted to Gaussian distribution. The use of Gaussian distribution as a function of $\mathrm{z}$ was inspired by the 2D SPT point-spread function (Equation (6)) but for the purpose of centroid determination, Gaussian is a good approximation [16].

$$
\begin{gathered}
\text { Gaussian for } z \text {-axis } \equiv A^{\prime} \cdot \exp \left(-\frac{\left(z-z_{0}\right)^{2}}{2 \sigma^{\prime 2}}\right) \\
A^{\prime}: \text { amplitude of Gaussian, } \sigma^{\prime}: \text { standard deviation of Gaussian }
\end{gathered}
$$

We emphasize here that there are pros and cons to each of the methods, so it is important to understand all those schemes and select appropriate methods for the specific purpose. The technical aspects of the two schemes can be found in the literature and, therefore, the pros and cons of scanning

\begin{tabular}{|c|c|c|c|}
\hline & Confocal & Epifluorescence & TIRF \\
\hline Pros & $\begin{array}{l}\text { No out-of-focus background } \\
\text { Sectioning along } z \text {-axis }\end{array}$ & $\begin{array}{l}\text { Rapid detection } \\
\text { Low signal loss } \\
\text { Deep penetration }\end{array}$ & $\begin{array}{l}\text { Rapid detection } \\
\text { Low background }\end{array}$ \\
\hline Cons & $\begin{array}{l}\text { Slow detection } \\
\text { Signal loss }\end{array}$ & High background & Small excitation depth \\
\hline
\end{tabular}
microscopy (confocal) and wide-filed microscopy (epifluorescence microscopy and total internal reflection microscopy or TIRF) are summarized in Table 1.

Table 1. Pros and cons of confocal, epifluorescence, and TIRF microscopy. 
It is easy to determine from Table 1 that these methods are complementary to each other and, as for the UCNP imaging, the epifluorescence microscopic technique was found to be the best [3]. For example, the high background stemming mainly from the solvent (medium) is simply removed by the rinsing solvent while preparing the immobilized cell samples. The $3 \mathrm{D}$ coordinates were determined upon reconstruction (Figure $3 \mathrm{~d}, \mathrm{e}$ ) and the outline of nuclei whose surface is covered with red fluorescent protein (RFP) is shown. Since RFP is photobleached quickly, the snapshot pictures of nuclei are taken and the laser turned off $(532 \mathrm{~nm})$. Moreover, in 3D images, the interesting point is whether the particles are inside and outside the organelles, such as nuclei and the mitochondria cell membrane, addressing the mechanism of internalization and release. It is worth noting that this 3D experiment was a combination of wide-field and z-scanning. The imaging speed was one 3D image per second, thus useful for fast dynamics $[16,45]$.

The method of confocal microscopy is based on a scanning scheme in all three ( $x-, y-$ and $z-)$ directions that has been already reviewed in many studies [68-70]. Although this method is appropriate for watching fixed structures or slow dynamics, it is usually difficult to track fast moving particles. One of the breakthroughs to this was the spinning-disk confocal scheme, whereby the imaging speed can be substantially increased while preserving the advantages of confocal microscopy [84-88]. That is, the fast $2 \mathrm{D}$ sectioning and z-scanning capability of spinning-disk confocal microscopy are good alternative ways of tracking UCNPs in 3D.

\section{Applications}

The SPT of nanoparticles at the cellular level can be engineered for efficient drug or gene delivery and sensing $[3-6,60,64,89]$. For example, the information from SPT analysis provides the endocytosis, delivery pathway, and arrival at the target [14,57].

\subsection{Delivery System}

In drug delivery systems where nanoparticles are used as carriers, the most important factor is the number of nanoparticles that are efficiently taken up by the cell. Zhang et al. reported that UCNPs with a higher surface charge can be more efficiently taken up by the cell [90]. The uptake efficiency of UCNP-PEI (positively charged, PEI = polyethyleneimine) was higher than that of UCNP-PAA (negatively charged, PAA = polyacrylamide) or UCNP-PVP (weak positively charged, $\mathrm{PVP}=$ polyvinyl pyrrolidone) over the initial $4 \mathrm{~h}$. This was attributed simply to the electrostatic interaction between nanoparticles and the negatively charged cell membrane, which was suggested to be the main driving force behind the controlled cellular uptake of nanoparticles (Figure 3a-c). In addition, as the particle size increases, the role of the surface charge weakens and the particle shape becomes a major determining factor in the cellular uptake process. Thus, particles with a large surface-to-volume ratio were more efficiently taken up in the energy-dependent endocytosis process.

In addition to cellular uptake in the delivery system, another important factor is precise targeting. Previous studies have shown that it is challenging to quantify the targeting efficiency at the cellular level as many nanoparticles are taken up by the cells and the whole image is analyzed. However, as shown in several previous studies, SPT of UCNPs in combination with target staining can allow sufficient analysis of the targeting accuracy [45,91-95].

Gho et al. evaluated the uptake efficiency and targeting effect of UCNPs with cell-penetrated peptides using the TAT peptide (cell penetration and nuclear-targeted sequences) conjugated with UCNP and UCNP-PAA [45]. The uptake efficiency of TAT-peptide-conjugated UCNP and UCNP-PAA did not differ significantly during the first $4 \mathrm{~h}$. However, after $24 \mathrm{~h}$, UCNP-TAT (which had a strong positive charge and was targeted to the cell nucleus) remains in the cells, whereas UCNP-PAA is mostly excreted outside the cells, indicating that its targeting effect was better than that of UCNP-PAA (Figure 3d). In particular, the real-time 3D tracking of UCNP using these methods can provide useful information regarding the intracellular pathways of UCNP in live cells. Simultaneously tracking several single UCNPs can allow the analysis of relative movement (Figure 3e). This technique is 
highly advantageous for studying the effect of various intracellular structures on carrier transport in delivery systems.

Wang et al. [94] studied the delivery of doxorubicin, an anticancer drug, using UCNP. They used folic-acid-conjugated UCNP to target folate receptors that are present on various types of cancer cell surfaces. They elucidated the exact targeting effect by tracking the location of doxorubicin and single UCNPs. Liu et al. [95] studied a photodynamic system that induced the apoptosis of cancer cells by targeting mitochondria and generating mitochondrial reactive oxygen species (mitoROS) through a photosensitizer-conjugated UCNP. In particular, they demonstrated that the heme-containing cytochrome c produced in this process could be used as an indicator for apoptosis studies by altering the upconversion luminescence signal. They stained the mitochondria with a fluorescent dye and tracked the location of a single UCNP to ensure that the correct target was reached.
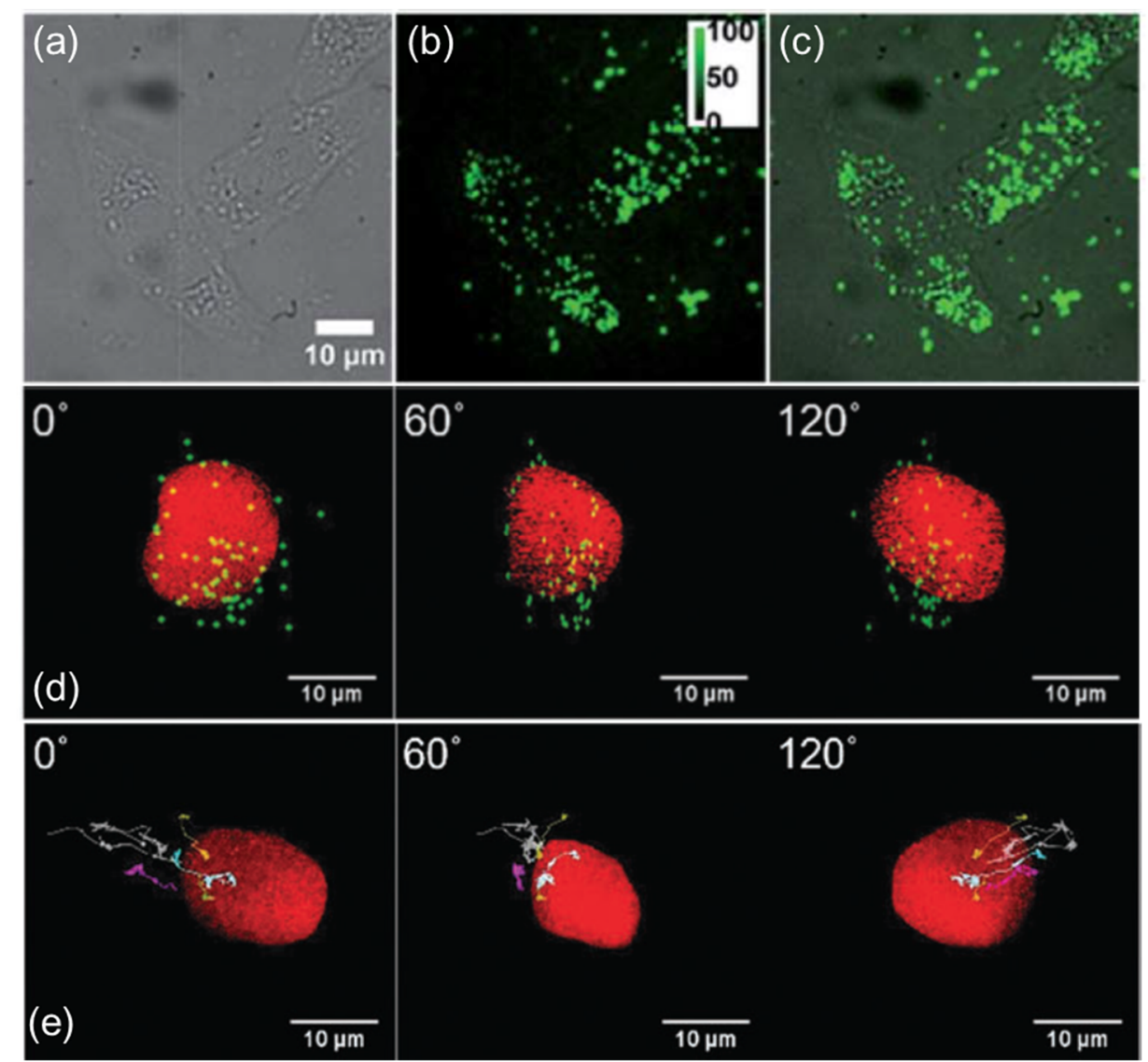

Figure 3. $2 \mathrm{D}$ and $3 \mathrm{D}$ SPT images. $(\mathbf{a}-\mathbf{c})$ The fluorescence microscopy characterization of HeLa cells co-cultured with polymer-modified UCNPs. (a) bright-field, (b) fluorescence and (c) merged microscopy images [90]. (d) The images from various angles (at $0^{\circ}, 60^{\circ}$ and $120^{\circ}$ ) for UCNP-phospholipid-PEG-TAT. (e) The 3D trajectories from various angles (at $0^{\circ}, 60^{\circ}$ and $120^{\circ}$ ) for UCNP-phospholipid-PEG-NH ${ }^{3+}$ [45]. Reproduced from [90] with permission from Royal Society of Chemistry and [45] by permission of the PCCP Owner Societies. Copyright 2018 Royal Society of Chemistry.

\subsection{Biosensing}

In addition to drug delivery, SPT technology is actively used in biosensing. An acidic $\mathrm{pH}$ inside cells is an important indicator of intracellular dysfunction, such as cancer [96]. Therefore, the development of an effective $\mathrm{pH}$ sensor that is capable of instantly measuring and imaging rapid $\mathrm{pH}$ changes within cells would be an important breakthrough [96-98]. In particular, due to their photostability and use of NIR excitation, UCNP-based $\mathrm{pH}$-sensitive probes can function as a sensor 
inside living cells for an extended period of time. Arppe et al. [96] developed a pH sensor that covalently linked a fluorogenic $\mathrm{pH}$-dependent dye (pHrodo ${ }^{\mathrm{TM}} \mathrm{Red}$ ) to the surface of UCNP. However, the fluorescence emission of $\mathrm{pHrodo}^{\mathrm{TM}}$ Red significantly decreases with decreasing $\mathrm{pH}$ and cannot be used for long-term live cell imaging due to the phototoxicity of the $532 \mathrm{~nm}$ laser wavelength used to excite this dye, which shows photobleaching and photoblinking. However, $\mathrm{pHrodo}^{\mathrm{TM}}$ Red conjugated to UCNP was used as a stable sensor via the energy transfer effect. Hence, this group was able to develop a $\mathrm{pH}$ sensor with a dynamic $\mathrm{pH}$ range of 2.5-7.2 and demonstrated its function as a nanoscale pH sensor in living HeLa cells.

Similarly, Näreoja et al. [98] used pHrodo conjugated to PEI-coated UCNP in a study of the regulation of intracellular vesicle acidity. Cells were treated with UCNP-PEI-pHrodo for $16 \mathrm{~h}$. After this, the intracellular localized UCNP in the cells were monitored and the intracellular environment was classified into three categories, e.g., cytoplasmic ( $\mathrm{pH}$ 7.2-7.5), endosomal (6.0-7.2) and lysosomal $(<6.0)$. Most of the UCNPs $(95 \%)$ were discharged from endosomes into the neutral environment that was located in lysosomes and endosomes. Thus, they could be used as sensors for measuring $\mathrm{pH}$ change inside the endoplasmic reticulum (Figure 4). These results would be used as a very useful tool for detecting the change in $\mathrm{pH}$ in a cellular level environment by imaging the position of the endoplasmic reticulum in real time. This would involve recording the change of the emission wavelength as a function of $\mathrm{pH}$ change at the single particle level.
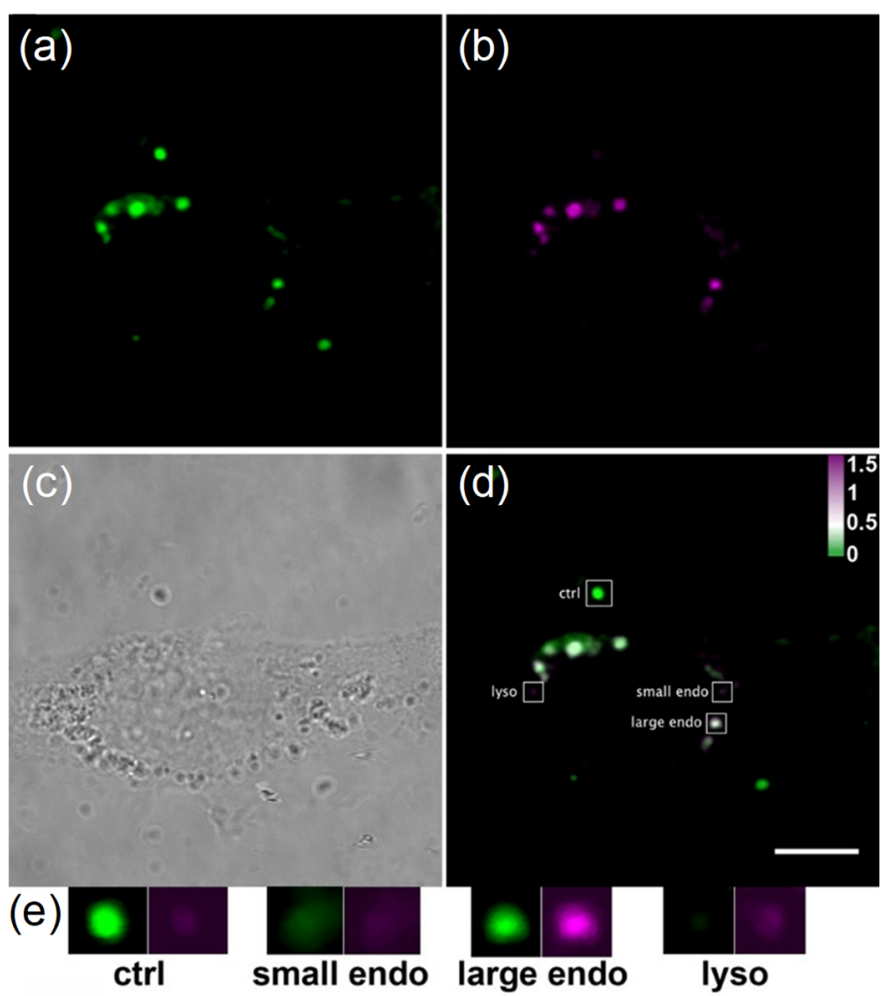

Figure 4. Ratiometric imaging of $\mathrm{pH}$ probes reveals their localization in three types of microenvironment. (a) Localization of UCNPs detected using $980 \mathrm{~nm}$ excitation, (b) sensitized upconversion resonance energy transfer emission from pHrodo Red, (c) bright-field, (d) an overlaid ratiometric image of $\mathrm{pH}$ nanoprobes with different ratios depending on the localization. Scale bar $10 \mu \mathrm{m}$. The enlarged insets (e) show different ratios in extracellular (ctrl), small endosome, large endosome, and lysosome. Brightness of insets is increased by 10 gray level units from the overlaid image (d) for better visibility [98]. Reprinted from [98] with permission from American Chemical Society. Copyright 2017 American Chemical Society. 
Another important function of biosensors is heat sensing via thermosensor systems [99]. Thermal mapping requires fluorescent nanoprobes with good biocompatibility and high thermal sensitivity to obtain submicron spatial resolution and subdegree thermal resolution. Shi et al. [100] treated NIH-3T3 cells with $\mathrm{NaYF}_{4}: \mathrm{Yb}^{3+}, \mathrm{Er}^{3+} @ \mathrm{NaYF}_{4}: \mathrm{Yb}^{3+}, \mathrm{Nd}^{3+}$ core-shell nanoparticles to measure the intracellular temperature (Figure 5).

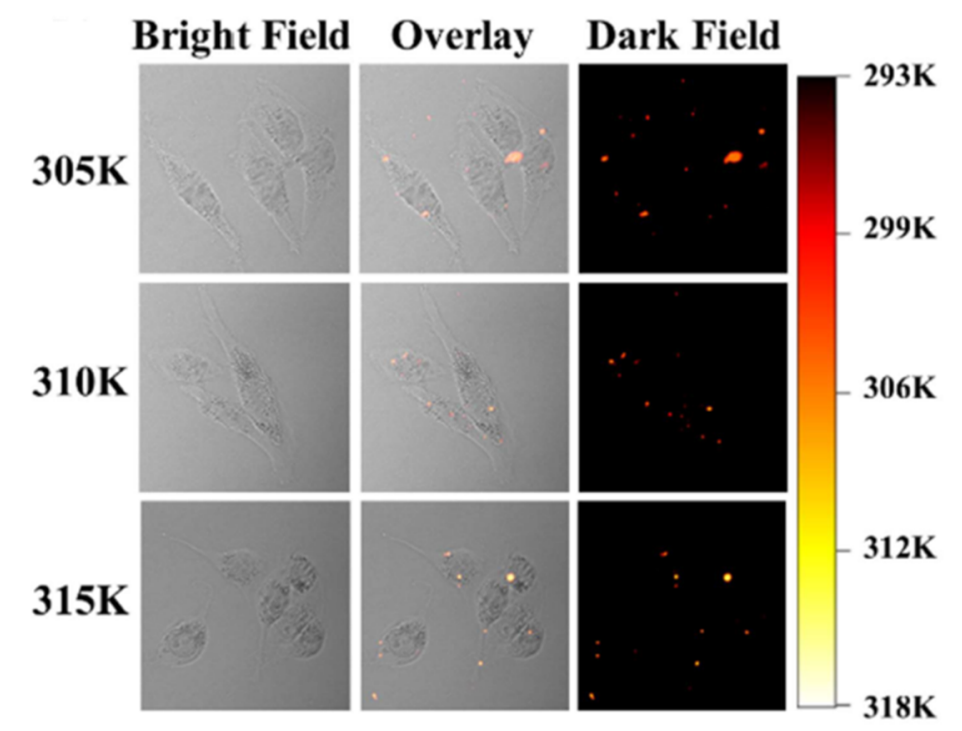

Figure 5. Thermal images of NIH-3T3 cells treated with external heating [100]. Adapted from [100] with permission from IOPScience. Copyright 2018 IOPScience.

Oxygen sensors have also been developed as the oxygen activity can be used for tumor diagnosis at the cellular level. Xu et al. [101] developed a multifunctional nanocomposite composed of light-emitting UCNPs capped with mesoporous silica and loaded with an oxygen-sensitive luminescent ruthenium complex. The red downconversion luminescence (at excitation/emission peaks of $455 / 606 \mathrm{~nm}$ ) was rapidly reduced by oxygen and was able to rapidly indicate the oxygen concentration in hepatocellular carcinoma cells (HepG-2).

Such UCNP-based biosensors should be able to quickly and accurately measure changes in the specific parts of the cell. Therefore, SPT is indispensable in this field and accurate information that is collected at the cellular level by SPT analysis can be used in various important and specific applications, such as disease diagnosis.

\section{Perspectives}

We have briefly reviewed the principle of upconversion, usage of UCNPs in live cell imaging and SPT. SPT and imaging technology have been developed such that one can obtain nanometer (spatial) resolutions for imaging cells and tissues [27,29,32,40,102-105]. The bottleneck is more likely to be probes due to their photostability and targeting capability. Throughout this review, the advantages of using UCNPs as the probe were emphasized, but determining the specific targeting chemistry is still in its early stages. Medicinal chemists trying to find appropriate chemical drugs should be aware of the importance of imaging technology, such as SPT, and willing to incorporate it with this other technique. For example, photodynamic therapy requires sensitizing molecules attached to the nanoparticles and a laser system that triggers the reactive oxygen species (ROS) is produced $[17,19,106]$. A better understanding of the mechanism for the delivery of nanoparticles at the single particle level and chemical stability and reactivity is a prerequisite for early and accurate diagnosis and therapy [107-109]. 
Acknowledgments: This work was supported by the GIST Research Institute (GRI, 2018) and the National Research Foundation (NRF) (NRF-2017R1A2B3005414 and NRF-2013K1A1A2A02050616) of South Korea. Y.H.S. was supported by the NRF (NRF-2016R1A6A3A11932194) of South Korea.

Conflicts of Interest: The authors declare no conflict of interest.

\section{References}

1. Auzel, F. Upconversion and Anti-Stokes Processes with f and d Ions in Solids. Chem. Rev. 2004, 104, $139-173$. [CrossRef] [PubMed]

2. Haase, M.; Schäfer, H. Upconverting nanoparticles. Angew. Chem. Int. Ed. 2011, 50, 5808-5829. [CrossRef]

3. Park, Y.I.; Lee, K.T.; Suh, Y.D.; Hyeon, T. Upconverting nanoparticles: A versatile platform for wide-field two-photon microscopy and multi-modal in vivo imaging. Chem. Soc. Rev. 2015, 44, 1302-1317. [CrossRef] [PubMed]

4. Chen, G.; Qiu, H.; Prasad, P.N.; Chen, X. Upconversion nanoparticles: Design, Nanochemistry and Applications in Theranostics. Chem. Rev. 2014, 114, 5161-5214. [CrossRef] [PubMed]

5. Mahata, M.K.; Bae, H.; Lee, K.T. Upconversion luminescence Sensitized pH-Nanoprobes. Molecules 2017, 22, 2064. [CrossRef] [PubMed]

6. Liu, X.; Yan, C.H.; Capobianco, J.A. Photon upconversion nanomaterials. Chem. Soc. Rev. 2015, 44, $1299-1301$. [CrossRef]

7. Weissleder, R. A clearer vision for in vivo imaging. Nat. Biotechnol. 2001, 19, 316-317. [CrossRef] [PubMed]

8. Li, Z.; Zhang, Y.; Jiang, S. Multicolor Core/Shell-Structured Upconversion Fluorescent Nanoparticles. Adv. Mater. 2008, 20, 4765-4769. [CrossRef]

9. le Masne de Chermont, Q.; Chaneac, C.; Seguin, J.; Pelle, F.; Maitrejean, S.; Jolivet, J.-P.; Gourier, D.; Bessodes, M.; Scherman, D. Nanoprobes with near-infrared persistent luminescence for in vivo imaging. Proc. Natl. Acad. Sci. USA 2007, 104, 9266-9271. [CrossRef]

10. Frangioni, J.V. In vivo near-infrared fluorescence imaging. Curr. Opin. Chem. Biol. 2003, 7, 626-634. [CrossRef]

11. Hilderbrand, S.A.; Weissleder, R. Near-infrared fluorescence: Application to in vivo molecular imaging. Curr. Opin. Chem. Biol. 2010, 14, 71-79. [CrossRef] [PubMed]

12. Zipfel, W.R.; Williams, R.M.; Christie, R.; Nikitin, A.Y.; Hyman, B.T.; Webb, W.W. Live tissue intrinsic emission microscopy using multiphoton-excited native fluorescence and second harmonic generation. Proc. Natl. Acad. Sci. USA 2003, 100, 7075-7080. [CrossRef] [PubMed]

13. Bae, Y.M.; Park, Y.I.; Nam, S.H.; Kim, J.H.; Lee, K.; Kim, H.M.; Yoo, B.; Choi, J.S.; Lee, K.T.; Hyeon, T.; et al. Endocytosis, intracellular transport and exocytosis of lanthanide-doped upconverting nanoparticles in single living cells. Biomaterials 2012, 33, 9080-9086. [CrossRef] [PubMed]

14. Nam, S.H.; Bae, Y.M.; Park, Y.I.; Kim, J.H.; Kim, H.M.; Choi, J.S.; Lee, K.T.; Hyeon, T.; Suh, Y.D. Long-Term Real-Time Tracking of Lanthanide Ion Doped Upconverting Nanoparticles in Living Cells. Angew. Chem. Int. Ed. 2011, 123, 6217-6221. [CrossRef]

15. Xu, C.T.; Svensson, N.; Axelsson, J.; Svenmarker, P.; Somesfalean, G.; Chen, G.; Liang, H.; Liu, H.; Zhang, Z.; Andersson-Engels, S. Autofluorescence insensitive imaging using upconverting nanocrystals in scattering media. Appl. Phys. Lett. 2008, 93, 2006-2009. [CrossRef]

16. Jo, H.L.; Song, Y.H.; Park, J.; Jo, E.-J.; Goh, Y.; Shin, K.; Kim, M.-G.; Lee, K.T. Fast and background-free three-dimensional (3D) live-cell imaging with lanthanide-doped upconverting nanoparticles. Nanoscale 2015, 7, 19397-19402. [CrossRef]

17. Idris, N.M.; Gnanasammandhan, M.K.; Zhang, J.; Ho, P.C.; Mahendran, R.; Zhang, Y. In vivo photodynamic therapy using upconversion nanoparticles as remote-controlled nanotransducers. Nat. Med. 2012, 18, 1580-1585. [CrossRef]

18. Yang, Y.; Shao, Q.; Deng, R.; Wang, C.; Teng, X.; Cheng, K.; Cheng, Z.; Huang, L.; Liu, Z.; Liu, X.; et al. In Vitro and In Vivo Uncaging and Bioluminescence Imaging by Using Photocaged Upconversion Nanoparticles. Angew. Chem. Int. Ed. 2012, 51, 3125-3129. [CrossRef]

19. Wang, C.; Cheng, L.; Liu, Z. Upconversion Nanoparticles for Photodynamic Therapy and Other Cancer Therapeutics. Theranostics 2013,3,317-330. [CrossRef] 
20. Chen, S.; Weitemier, A.Z.; Zeng, X.; He, L.; Wang, X.; Tao, Y.; Huang, A.J.Y.; Hashimotodani, Y.; Kano, M.; Iwasaki, H.; et al. Near-infrared deep brain stimulation via upconversion nanoparticle-mediated optogenetics. Science 2018, 359, 679-684. [CrossRef]

21. Wu, S.; Han, G.; Milliron, D.J.; Aloni, S.; Altoe, V.; Talapin, D.V.; Cohen, B.E.; Schuck, P.J. Non-blinking and photostable upconverted luminescence from single lanthanide-doped nanocrystals. Proc. Natl. Acad. Sci. USA 2009, 106, 10917-10921. [CrossRef] [PubMed]

22. Park, Y.I.; Kim, J.H.; Lee, K.T.; Jeon, K.S.; Na, H.B.; Yu, J.H.; Kim, H.M.; Lee, N.; Choi, S.H.; Baik, S.I.; et al. Nonblinking and Nonbleaching Upconverting Nanoparticles as an Optical Imaging Nanoprobe and T1 Magnetic Resonance Imaging Contrast Agent. Adv. Mater. 2009, 21, 4467-4471. [CrossRef]

23. Shin, K.; Jung, T.; Lee, E.; Lee, G.; Goh, Y.; Heo, J.; Jung, M.; Jo, E.J.; Lee, H.; Kim, M.G.; et al. Distinct mechanisms for the upconversion of NaYF4:Yb3+, Er3+ nanoparticles revealed by stimulated emission depletion. Phys. Chem. Chem. Phys. 2017, 19, 9739-9744. [CrossRef] [PubMed]

24. Wang, F.; Wen, S.; He, H.; Wang, B.; Zhou, Z.; Shimoni, O.; Jin, D. Microscopic inspection and tracking of single upconversion nanoparticles in living cells. Light Sci. Appl. 2018, 7, 18007-18012. [CrossRef]

25. Saxton, M.J. Single-particle tracking: Connecting the dots. Nat. Methods 2008, 5, 671-672. [CrossRef] [PubMed]

26. Manzo, C.; Garcia-Parajo, M.F. A review of progress in single particle tracking: From methods to biophysical insights. Rep. Prog. Phys. 2015, 78, 124601-124629. [CrossRef] [PubMed]

27. Shen, H.; Tauzin, L.J.; Baiyasi, R.; Wang, W.; Moringo, N.; Shuang, B.; Landes, C.F. Single Particle Tracking: From Theory to Biophysical Applications. Chem. Rev. 2017, 117, 7331-7376. [CrossRef] [PubMed]

28. Resch-Genger, U.; Grabolle, M.; Cavaliere-Jaricot, S.; Nitschke, R.; Nann, T. Quantum dots versus organic dyes as fluorescent labels. Nat. Methods 2008, 5, 763-775. [CrossRef]

29. Liu, Y.; Lu, Y.; Yang, X.; Zheng, X.; Wen, S.; Wang, F.; Vidal, X.; Zhao, J.; Liu, D.; Zhou, Z.; et al. Amplified stimulated emission in upconversion nanoparticles for super-resolution nanoscopy. Nature 2017, 543, $229-233$. [CrossRef]

30. Zhan, Q.; Liu, H.; Wang, B.; Wu, Q.; Pu, R.; Zhou, C.; Huang, B.; Peng, X.; Ågren, H.; He, S. Achieving hith-efficiency emission depletion nanoscopy by employing cross relaxation in upconversion nanoparticles. Nat. Commun. 2017, 8, 1-11. [CrossRef]

31. Chen, C.; Wang, F.; Wen, S.; Su, Q.P.; Wu, M.C.L.; Liu, Y.; Wang, B.; Li, D.; Shan, X.; Kianinia, M.; et al. Multi-photon near-infrared emission saturation nanoscopy using upconversion nanoparticles. Nat. Commun. 2018, 9, 1-6. [CrossRef] [PubMed]

32. Jin, D.; Xi, P.; Wang, B.; Zhang, L.; Enderlein, J.; Oijen, A.M.V. Nanoparticles for super-resolution microscopy and single-molecule tracking. Nat. Methods 2018, 15, 415-423. [CrossRef]

33. Pinaud, F.; Clarke, S.; Sittner, A.; Dahan, M. Probing cellular events, one quantum dot at a time. Nat. Methods 2010, 7, 275-285. [CrossRef] [PubMed]

34. Chan, W.C.W.; Maxwell, D.J.; Gao, X.; Bailey, R.E.; Han, M.; Nie, S. Luminescent quantum dots for multiplexed biological detection and imaging. Anal. Biotechnol. 2002, 13, 40-46. [CrossRef]

35. Michalet, X.; Pinaud, F.F.; Bentolila, L.A.; Tasy, J.M.; Doose, S.; Li, J.J.; Sundaresan, G.; Wu, A.M.; Gambhir, S.S.; Weiss, S. Quantum Dots for Live Cells, in Vivo Imaging and Diagnostics. Science 2005, 307, $538-545$. [CrossRef]

36. Alivisatos, A.P. Semiconductor Clusters, Nanocrystals and Quantum Dots. Science 1996, $271,933-937$. [CrossRef]

37. Heer, S.; Kömpe, K.; Güdel, H.U.; Haase, M. Highly Efficient Multicolour Upconversion Emission in Transparent Colloids of Lanthanide-Doped NaYF4 Nanocrystals. Adv. Mater. 2004, 16, 2102-2105. [CrossRef]

38. Gargas, D.J.; Chan, E.M.; Ostrowski, A.D.; Aloni, S.; Altoe, M.V.P.; Barnard, E.S.; Sanii, B.; Urban, J.J.; Milliron, D.J.; Cohen, B.E.; et al. Engineering bright sub-10-nm upconverting nanocrystals for single-molecule imaging. Nat. Nanotechnol. 2014, 9, 300-305. [CrossRef]

39. Thompson, R.E.; Larson, D.R.; Webb, W.W. Precise nanometer localization analysis for individual fluorescent probes. Biophys. J. 2002, 82, 2775-2783. [CrossRef]

40. Von Diezmann, A.; Shechtman, Y.; Moerner, W.E. Three-Dimensional Localization of Single Molecules for Super- Resolution Imaging and Single-Particle Tracking. Chem. Rev. 2017, 117, 7244-7275. [CrossRef]

41. Cheezum, M.K.; Walker, W.F.; Guilford, W.H. Quantitative Comparison of Algorithms for Tracking Single Fluorescent Particles. Biophys. J. 2001, 81, 2378-2388. [CrossRef] 
42. Chenouard, N.; Smal, I.; De Chaumont, F.; Maška, M.; Sbalzarini, I.F.; Gong, Y.; Cardinale, J.; Carthel, C.; Coraluppi, S.; Winter, M.; et al. Objective comparison of particle tracking methods. Nat. Methods 2014, 11, 281-290. [CrossRef]

43. Metzler, R.; Jeon, J.H.; Cherstvy, A.G.; Barkai, E. Anomalous diffusion models and their properties: Non-stationarity, non-ergodicity and ageing at the centenary of single particle tracking. Phys. Chem. Chem. Phys. 2014, 16, 24128-24164. [CrossRef] [PubMed]

44. Wennmalm, S.; Simon, S.M. Studying Individual Events in Biology. Annu. Rev. Biochem. 2007, 76, 419-446. [CrossRef] [PubMed]

45. Goh, Y.; Song, Y.H.; Lee, G.; Bae, H.; Mahata, M.K.; Lee, K.T. Cellular uptake efficiency of nanoparticles investigated by three-dimensional imaging. Phys. Chem. Chem. Phys. 2018, 20, 11359-11368. [CrossRef] [PubMed]

46. Saxton, M.J. SINGLE-PARTICLE TRACKING: Applications to Membrane Dynamics. Annu. Rev. Biophys. Biomol. Struct. 1997, 26, 373-399. [CrossRef]

47. Bräuchle, C.; Lamb, D.C.; Michaelis, J. Single Particle Tracking and Single Molecule Energy Transfer; John Wiley \& Sons: Hoboken, NJ, USA, 2009.

48. Meijering, E.; Dzyubachyk, O.; Smal, I.; Cappellen, W.A. Tracking in cell and developmental biology. Semin. Cell Dev. Biol. 2009, 20, 894-902. [CrossRef] [PubMed]

49. Suh, J.; Dawson, M.; Hanes, J. Real-time multiple-particle tracking: Applications to drug and gene delivery. Adv. Drug Deliv. Rev. 2005, 57, 63-78. [CrossRef]

50. Cognet, L.; Leduc, C.; Lounis, B. Advances in live-cell single-particle tracking and dynamic super-resolution imaging. Curr. Opin. Chem. Biol. 2014, 20, 78-85. [CrossRef]

51. Hirokawa, N. Kinesin and Dynein Superfamily Proteins and the Mechanism of Organelle Transport. Science 2005, 279, 519-526. [CrossRef]

52. Hancock, W.O. Bidirectional cargo transport: Moving beyond tug of war. Nat. Rev. Mol. Cell Biol. 2014, 15, 615-628. [CrossRef] [PubMed]

53. Kam, N.W.S.; Jessop, T.C.; Wender, P.A.; Dai, H. Nanotube Molecular Transporters: Internalization of Carbon Nanotube-Protein Conjugates into Mammalian Cells. J. Am. Chem. Soc. 2004, 126, 6850-6851. [CrossRef] [PubMed]

54. Pantarotto, D.; Briand, J.P.; Prato, M.; Bianco, A. Translocation of bioactive peptides across cell membranes by carbon nanotubes. Chem. Commun. 2004, 1, 16-17. [CrossRef] [PubMed]

55. Kam, N.W.S.; Liu, Z.; Dai, H. Carbon nanotubes as intracellular transporters for proteins and DNA: An investigation of the uptake mechanism and pathway. Angew. Chem. Int. Ed. 2006, 45, 577-581. [CrossRef] [PubMed]

56. Chithrani, B.D.; Chan, W.C.W. Elucidating the Mechanism of Cellular Uptake and Removal of Protein-Coated Gold Nanoparticles of Different Sizes and Shapes. Nano Lett. 2007, 7, 1542-1550. [CrossRef]

57. Jin, H.; Heller, D.A.; Strano, M.S. Single-Particle Tracking of Endocytosis and Exocytosis of Single-Walled Carbon Nanotubes in NIH-3T3 Cell. Nano Lett. 2008, 8, 1577-1585. [CrossRef] [PubMed]

58. Cho, K.; Wang, X.; Nie, S.; Chen, Z.G.; Shin, D.M. Therapeutic Nanoparticles for Drug Delivery in Cancer. Clin. Cancer Res. 2008, 14, 1310-1317. [CrossRef]

59. Jong, W.H.D.; Borm, P.J. Drug delivery and nanoparticles: Applications and hazards. Int. J. Nanomed. 2008, 3, 133-149. [CrossRef]

60. Yang, D.; Ma, P.; Hou, Z.; Cheng, Z.; Li, C.; Lin, J. Current advances in lanthanide ion (Ln3+)-based upconversion nanomaterials for drug delivery. Chem. Soc. Rev. 2015, 44, 1416-1448. [CrossRef]

61. Blanco, E.; Shen, H.; Ferrari, M. Princeples of nanoparticle design for overcoming biological barriers to drug delivery. Nat. Biotechnol. 2015, 33, 941-951. [CrossRef]

62. Dong, H.; Du, S.R.; Zheng, X.Y.; Lyu, G.M.; Sun, L.D.; Li, L.D.; Zhang, P.Z.; Zhang, C.; Yan, C.H. Lanthanide Nanoparticles: From Design toward Bioimaging and Therapy. Chem. Rev. 2015, 115, 10725-10815. [CrossRef]

63. Ulbrich, K.; Hola, K.; Vladimir, S.; Bakandritsos, A.; Tucek, J.; Zboril, R. Targeted Drug Delivery with Polymers and Magnetic Nanoparticles: Covalent and Noncovalent Approaches, Release Control and Clinical Studies. Chem. Rev. 2016, 116, 5338-5431. [CrossRef]

64. Karimi, M.; Zangabad, P.S.; Baghaee-ravari, S.; Ghazadeh, M.; Mirshekari, H.; Hamblin, M.R. Smart Nanostructures for Cargo Delivery: Uncaging and Activating by Light. J. Am. Chem. Soc. 2017, 139, 4584-4610. [CrossRef] 
65. Zhang, S.; Li, J.; Lykotrafitis, G.; Bao, G.; Suresh, S. Size-Dependent Endocytosis of Nanoparticles. Adv. Matter. 2009, 21, 419-424. [CrossRef] [PubMed]

66. Jiang, W.E.N.; Kim, B.Y.S.; Rutka, J.T.; Chan, W.C.W. Nanoparticle-mediated cellular response is size-dependent. Nat. Nanotechnol. 2008, 3, 145-150. [CrossRef] [PubMed]

67. Jin, H.; Heller, D.A.; Sharma, R.; Strano, M.S. Size-Dependent Cellular Uptake and Expulsion of Single-Walled Carbon Nanotubes: Single Particle Tracking and Nanoparticles. ACS Nano 2009, 3, 149-158. [CrossRef]

68. Webb, R.H. Confocal optical microscopy. Rep. Prog. Phys. 1996, 59, 427-471. [CrossRef]

69. Huisken, J.; Swoger, J.; Bene, F.D.; Wittbrodt, J.; Stelzer, E.H.K. Live Embryos by Selective Plane Illumination Microscopy. Science 2004, 305, 1007-1010. [CrossRef]

70. Schermelleh, L.; Carlton, P.M.; Haase, S.; Shao, L.; Winoto, L.; Kner, P.; Burke, B.; Cardoso, M.C.; Agard, D.A.; Gustafsson, M.G.L.; et al. Subdiffraction Multicolor Imaging of the Nuclear Periphery with 3D Structured Illumination Microscopy. Science 2008, 320, 1332-1337. [CrossRef]

71. Marquet, P.; Rappaz, B.; Magistretti, P.J.; Cuche, E.; Emery, Y.; Colomb, T.; Depeursinge, C. Digital holographic microscopy: A noninvasive contrast imaging technique allowing quantitative visualization of living cells with subwavelength axial accuracy. Opt. Lett. 2005, 30, 468-470. [CrossRef]

72. Rappaz, B.; Marquet, P.; Cuche, E.; Emery, Y.; Depeursinge, C.; Magistretti, P.J. Measurement of the integral refractive index and dynamic cell morphometry of living cells with digital holographic microscopy. Opt. Express 2005, 13, 9361-9373. [CrossRef] [PubMed]

73. Ortega-Arroyo, J.; Kukura, P. Interferometric scattering microscopy (iSCAT): New frontiers in ultrafast and ultrasensitive optical microscopy. Phys. Chem. Chem. Phys. 2012, 14, 15625-15636. [CrossRef] [PubMed]

74. Andrecka, J.; Arroyo, J.O.; Takagi, Y.; Wit, G.; Fineberg, A.; MacKinnon, L.; Young, G.; Sellers, J.R.; Kukura, P. Structural dynamics of myosin 5 during processive motion revealed by interferometric scattering microscopy. eLife 2015, 4, e05413. [CrossRef] [PubMed]

75. Pavani, S.R.P.; Thompson, M.A.; Biteen, J.S.; Lord, S.J.; Liu, N.; Twieg, R.J.; Piestun, R.; Moerner, W.E. Three-dimensional, single-molecule fluorescence imaging beyond the diffraction limit by using a double-helix point spread function. Proc. Natl. Acad. Sci. USA 2009, 106, 2995-2999. [CrossRef] [PubMed]

76. Toprak, E.; Balci, H.; Blehm, B.H.; Selvin, P.R. Three-Dimensional Particle Tracking via Bifocal Imaging. Nano Lett. 2007, 7, 2043-2045. [CrossRef] [PubMed]

77. Liu, Y.-L.; Perillo, E.P.; Liu, C.; Yu, P.; Chou, C.-K.; Hung, M.-C.; Dunn, A.K.; Yeh, H.-C. Segmentation of 3D Trajectories Acquired by TSUNAMI Microscope: An Application to EGFR Trafficking. Biophys. J. 2016, 111, 2214-2227. [CrossRef]

78. Huang, B.; Wang, W.; Bates, M.; Zhuang, X. Three-Dimensional Super-Resolution Reconstruction Microscopy. Science 2008, 319, 810-814. [CrossRef]

79. Jones, S.A.; Shim, S.; He, J.; Zhuang, X. Fast, three-dimensional super-resolution imaging of live cells. Nat. Methods 2011, 8, 499-505. [CrossRef]

80. Jia, S.; Vaughan, J.C.; Zhuang, X. Isotropic three-dimensional super-resolution imaging with a self-bending point spread function. Nat. Photonics 2014, 8, 302-306. [CrossRef]

81. Axelrod, D. Total Internal Reflection Fluorescence Microscopy in Cell Biology. Traffic 2001, 2, 764-774. [CrossRef]

82. Schneckenburger, $\mathrm{H}$. Total internal reflection fluorescence microscopy: Technical innovations and novel applications. Curr. Opin. Biotechnol. 2005, 16, 13-18. [CrossRef] [PubMed]

83. Babcock, H.; Sigal, Y.M.; Zhuang, X. A high-density 3D localization algorithm for stochastic optical reconstruction microscopy. Opt. Nanoscopy 2012, 1, 1-10. [CrossRef] [PubMed]

84. Nakano, A. Spinning-disk confocal microscopy-A cutting-edge tool for imaging of membrane traffic. Cell Struct. Funct. 2002, 27, 349-355. [CrossRef] [PubMed]

85. Adams, M.C.; Salmon, W.C.; Gupton, S.L.; Cohan, C.S.; Wittmann, T.; Prigozhina, N.; Waterman-storer, C.M. A high-speed multispectral spinning-disk confocal microscope system for fluorescent speckle microscopy of living cells. Methods 2003, 29, 29-41. [CrossRef]

86. Egeblad, M.; Ewald, A.J.; Askautrud, H.A.; Truitt, M.L.; Welm, B.E.; Bainbridge, E.; Peeters, G.; Krummel, M.F.; Werb, Z. Visualizing stromal cell dynamics in different tumor microenvironments by spinning disk confocal microscopy. Dis. Model. Mech. 2008, 1, 155-167. [CrossRef] [PubMed] 
87. Jenne, C.N.; Wong, C.H.Y.; Petri, B.; Kubes, P. The Use of Spinning-Disk Confocal Microscopy for the Intravital Analysis of Platelet Dynamics in Response to Systemic and Local Inflammation. PLoS ONE 2011, 6, 1-13. [CrossRef] [PubMed]

88. Hayashi, S.; Okada, Y. Ultrafast superresolution fluorescence imaging with spinning disk confocal microscope optics. Mol. Biol. Cell 2015, 26, 1743-1751. [CrossRef]

89. Wen, S.; Zhou, J.; Zheng, K.; Bednarkiewicz, A.; Liu, X.; Jin, D. Advances in highly doped upconversion nanoparticles. Nat. Commun. 2018, 9, 1-12. [CrossRef] [PubMed]

90. Zhang, D.; Wei, L.; Zhong, M.; Xiao, L.; Li, H.W.; Wang, J. The morphology and surface charge-dependent cellular uptake efficiency of upconversion nanostructures revealed by single-particle optical microscopy. Chem. Sci. 2018, 9, 5260-5269. [CrossRef]

91. Yang, Y.; Liu, F.; Liu, X.; Xing, B. NIR light controlled photorelease of siRNA and its targeted intracellular delivery based on upconversion nanoparticles. Nanoscale 2013, 5, 231-238. [CrossRef]

92. Dcona, M.M.; Yu, Q.; Capobianco, J.A.; Hartman, M.C.T. Near infrared light mediated release of doxorubicin using upconversion nanoparticles. Chem. Commun. 2015, 51, 8477-8479. [CrossRef]

93. Chien, Y.H.; Chou, Y.L.; Wang, S.W.; Hung, S.T.; Liau, M.C.; Chao, Y.J.; Su, C.H.; Yeh, C.S. Near-infrared light photocontrolled targeting, bioimaging and chemotherapy with caged upconversion nanoparticles in vitro and in vivo. ACS Nano 2013, 7, 8516-8528. [CrossRef] [PubMed]

94. Wang, C.; Cheng, L.; Liu, Z. Drug delivery with upconversion nanoparticles for multi-functional targeted cancer cell imaging and therapy. Biomaterials 2011, 32, 1110-1120. [CrossRef]

95. Liu, Y.; Zhang, J.; Zuo, C.; Zhang, Z.; Ni, D.; Zhang, C.; Wang, J.; Zhang, H.; Yao, Z.; Bu, W. Upconversion nano-photosensitizer targeting into mitochondria for cancer apoptosis induction and cyt c fluorescence monitoring. Nano Res. 2016, 9, 3257-3266. [CrossRef]

96. Arppe, R.; Näreoja, T.; Nylund, S.; Mattsson, L.; Koho, S.; Rosenholm, J.M.; Soukka, T.; Schäferling, M. Photon upconversion sensitized nanoprobes for sensing and imaging of pH. Nanoscale 2014, 6, 6837-6843. [CrossRef] [PubMed]

97. Li, C.; Zuo, J.; Zhang, L.; Chang, Y.; Zhang, Y.; Tu, L.; Liu, X.; Xue, B.; Li, Q.; Zhao, H.; et al. Accurate Quantitative Sensing of Intracellular $\mathrm{pH}$-based on Self-ratiometric Upconversion Luminescenct Nanoprobe. Sci. Rep. 2016, 6, 38617. [CrossRef] [PubMed]

98. Näreoja, T.; Deguchi, T.; Christ, S.; Peltomaa, R.; Prabhakar, N.; Fazeli, E.; Perälä, N.; Rosenholm, J.M.; Arppe, R.; Soukka, T.; et al. Ratiometric Sensing and Imaging of Intracellular pH Using Polyethylenimine-Coated Photon Upconversion Nanoprobes. Anal. Chem. 2017, 89, 1501-1508. [CrossRef] [PubMed]

99. Vetrone, F.; Naccache, R.; Zamarrón, A.; De La Fuente, A.J.; Sanz-Rodríguez, F.; Maestro, L.M.; Rodriguez, E.M.; Jaque, D.; Sole, J.G.; Capobianco, J.A. Temperature sensing using fluorescent nanothermometers. ACS Nano 2010, 4, 3254-3258. [CrossRef]

100. Shi, Z.; Duan, Y.; Zhu, X.; Wang, Q.; Li, D.; Hu, K.; Feng, W.; Li, F.; Xu, C. Dual functional NaYF4:Yb3+, Er 3+@NaYF4:Yb3+, Nd3+ core-shell nanoparticles for cell temperature sensing and imaging. Nanotechnology 2018, 29, 094001. [CrossRef]

101. Xu, S.; Yu, Y.; Gao, Y.; Zhang, Y.; Li, X.; Zhang, J.; Wang, Y.; Chen, B. Mesoporous silica coating NaYF4:Yb, Er@NaYF4 upconversion nanoparticles loaded with ruthenium(II) complex nanoparticles: Fluorometric sensing and cellular imaging of temperature by upconversion and of oxygen by downconversion. Microchim. Acta 2018, 185, 2-11. [CrossRef]

102. Hell, S.W.; Wichmann, J. Breaking the diffraction resolution limit by stimulated emission: Stimulated-emission-depletion fluorescence microscopy. Opt. Lett. 1994, 19, 780-782. [CrossRef] [PubMed]

103. Rust, M.J.; Bates, M.; Zhuang, X. Sub-diffraction-limit imaging by stochastic optical reconstruction microscopy (STORM). Nat. Methods 2006, 3, 793-795. [CrossRef] [PubMed]

104. Betzig, E.; Patterson, G.H.; Sougrat, R.; Lindwasser, O.W.; Olenych, S.; Bonifacino, J.S.; Davidson, M.W.; Lippincott-Schwartz, J.; Hess, H.F. Imaging intracellular fluorescent proteins at nanometer resolution. Science 2006, 313, 1642-1645. [CrossRef] [PubMed]

105. Hell, S.W. Far-Field Optical Nanoscopy. Science 2007, 316, 1153-1159. [CrossRef] [PubMed]

106. Dolmans, D.E.J.G.J.; Fukumura, D.; Jain, R.K. Photodynamic therapy for cancer. Nat. Rev. Cancer 2003, 3, 380-387. [CrossRef] [PubMed] 
107. Bechet, D.; Couleaud, P.; Frochot, C.; Viriot, M.L.; Guillemin, F.; Barberi-Heyob, M. Nanoparticles as vehicles for delivery of photodynamic therapy agents. Trends Biotechnol. 2008, 26, 612-621. [CrossRef] [PubMed]

108. Iversen, T.G.; Skotland, T.; Sandvig, K. Endocytosis and intracellular transport of nanoparticles: Present knowledge and need for future studies. Nano Today 2011, 6, 176-185. [CrossRef]

109. Lucky, S.S.; Soo, K.C.; Zhang, Y. Nanoparticles in photodynamic therapy. Chem. Rev. 2015, 115, $1990-2042$. [CrossRef] [PubMed] 